\title{
Networks and Partnerships of Global Governance:
}

\author{
Two Missing Legitimacies
}

\section{Mohamed Hamchi and Samia Rebiai}

Mohamed Hamchi is a Ph. D. candidate. He received his M.A. in International Relations at the University of Batna, Algeria, 2010. He has written a B. A. thesis on "WTO and Development in Developing Countries" and a Master thesis on "Pluralism and Hegemony in Internatioanl Relations Theories." Currently, he is working on "The Fifth Debate among International Relations Theories: Engaging Complexity Theory within the Field." His interests include International Relations Theory, Global Governance Studies, Critical Security Studies, Maghreb and EU Studies.

Samia Rebiai is a Ph. D. candidate. She received her M.A. in International Relations at the University of Constantine, Algeria, 2008. She has written a B. A. thesis on "The New World Order and Democracy" and a Master thesis on "Change Dynamics in Regional System: Eastern Asian Regional System as a Case Study." She is currently working on "Religions and International Relations." Her interests include Religions and International Relations, Conflict Analysis, Political Philosophy, International Relations Theory.

\begin{abstract}
Recently, literature on the problem of legitimacy in/of global governance (GG) institutions, networks and/or partnerships has considerably increased. However, as we argue in this article, the problem of legitimacy, in what James Rosenau called post-international relations, has remained inadequately problematized. We suggest that GG lacks two specific types of legitimacy: legitimacy of GG as a theory and legitimacy of GG as a practice. One further - still critical - shortcoming within the current theoretical framework is that of undervaluing normativity as a larger context within which the debate on legitimacy(ies) is still being fueled. The article is divided into three sections. The first section briefly offers a conceptual introduction to the article's terminology. Next, the second section attempts to bring the suggested multiplicity of GG's legitimacies into analysis. Finally, the third section draws conclusions about the significant value of bringing normativity back to GG studies and how it matters to the question of legitimacy.
\end{abstract}

Keywords: Global Governance; Legitimacy; Networks; Partnerships. 


\section{Introduction}

The term Global Governance ( $G G$ ) has been (self)established as a way to meeting the need to find a new terminology to describe and understand international relations ${ }^{44}$ in what Rosenau (1990) called a post-international era. As Müller and Lederer noted, there was in 2003 an explosion of literature on GG (Dingwerth and Pattberg, 2009:41). ${ }^{45}$ Moreover, there has been even an increase in the number of universities offering degrees in GG studies. Since then, the body of literature has kept certainly increasing addressing the problem of how we can "legitimize political action in a post-nation-state world." (Lederer and Müller, 2005:1) Following this definition, legitimacy and GG are conceptually so interlinked that the two concepts cannot be considered apart from each other.

In fact, the mass anti-globalization protests and its institutions, especially in Seattle 1999, have increasingly brought the question of GG legitimacy into a sophisticated debate, through what has been usually referred to as a crisis of legitimacy. Such a crisis has become more and more salient as policy making processes have become less open and less transparent, due to the proliferation of actors and stakeholders on the one hand, and due to the increasing complexity of global policy issues and challenges on the other hand.

In this context, GG networks/partnerships have emerged as a response to what has become known as the 'democratic deficit' and/or the 'participatory gap' in GG, because citizens, social actors and even private sector actors claim that they have been increasingly excluded from policy decision-making processes that affects their interests. Moreover, GG networks/partnerships have emerged as a solution to the problem of ineffectiveness and inefficiency of traditional international policy decision-making mechanisms in meeting the ever-complicating challenges of the post-national world.

Interestingly, despite the remarkably increase in the use of the set of concepts pointed out above, GG, networks, partnerships and (their) legitimacy, it happens that both academic and policy-making circles are still debating their meanings, their theoretical and their empirical value. However, the debate complicates more and more considerably when it comes to the question of legitimacy. Perhaps one of the most challenging aspects of such a debate is the fuzziness of the boundaries between the normative and the sociological meaning(s) of legitimacy.

\footnotetext{
44 We use international relations with initial capital letters (IR) to refer to the field of study while uses international relations with initial small letters to refer to the phenomenon.

45 In 1997, an Internet search revealed 3418 references to the term of GG. In 2004, the number had risen to almost 200,000 references. Whereas, by early 2008, the World Wide Web listed well over half a- million pages that include the term of GG.
} 
As we suggest, GG - and its recently conceptualized networks and partnerships lack in fact three specific types of legitimacy: legitimacy of GG as a theory, legitimacy of GG as a practice and legitimacy of GG even as a conception in the daily language of international politics scholars and practitioners as well. In order to develop these propositions, the article is divided into three sections. The first section briefly offers a conceptual introduction to the article's terminology - global governance, networks/partnerships, and legitimacy.

The second part is devoted to bringing the suggested multiplicity of GG's legitimacies into analysis. As to its legitimacy as a theory, we argue that although GG as a theory self-introduces as a non-traditional way of thinking in International Relations (IR) field, oppositely more or less to state-centric and materialist approaches. The theory has been still struggling for paradigmatic recognition within a field that still seems wellestablishedly dominated by traditional paradigm(s). In regard to its legitimacy as a practice, we develop two argumentations. First, we argue that GG is not so global, and that world politics has witnessed not the rise of GG, but $a$ rise of many not so GGs. This part of the article, sustained by statistic figures, discusses the problem of GG's 'geographical bias.' Second, we argue that although GG still undergoes a democratic deficit, debate on its legitimacy needs to go beyond the traditional lines around which the democratic deficit problematique is usually discussed.

Finally, the third concluding section attempts to draw conclusions about the significant value of bringing normativity back to GG studies and how it matters to the question of legitimacy. It argues that understanding legitimacy of GG normatively, more sociologically, and therefore more inter-subjectively, hopefully contributes to making GG a politicalaction project rather than a research programme.

\section{Definitions}

\subsection{Global Governance}

The term Global Governance can be simply juxtaposed with the traditional label International Relations (Dingwerth and Pattberg, 2009:42-44; Baylis and Smith, 2005:1-13). It refers to a shift from an inter-nation-al to a globe-al level of analysis on the one hand, and from inter-nation-al relations to complex global networks of interactions among different types of state as well as non-state actors on the other hand. However, it seems that GG has represented a conceptual alternative to the dilemmatic persistent absence of a world government. 
GG refers to governance processes at the global level. However, the global here includes other levels of interaction, inter-governmental, trans-governmental, transnational and supranational; these levels help to defining the actors involved, the governance resources used and the patterns how resources are exchanged among actors. Furthermore, the global denotes a world in which actors other than states play an increasingly important role, and in which decision-making processes are multilevel, connected both within and between states (Weiss and Kamran, 2009:69). The multitude of actors indeed reflects a dispersion of governance resources among them in a way that no actor, whatever its nature is, can hold them all together. The resources are political (exercising hard or/and soft control over other actors' behavior), financial, cognitive (knowledge and information), and normative (legitimacy of policies and institutions). Again, governance resources have been no longer aggregated at the hands of states/governments. ${ }^{46}$ The question of resources is very important when it comes to the rise of GG networks/partnerships.

The plurality of actors is not the only aspect of the increasing complexity of GG structure. Moreover, Rosenau (2006) conceives GG as a multiplication of authority spheres beyond the state, which implies that international politics has been no longer an exclusive domain for the state, nor even for the actors deriving their authority from the state, such as international (governmental) organizations. Authority, within the framework of GG, is not only characterized by a multiplicity of spheres; it is also relocated and even redistributed. Authority has been relocated from the political to the economical and even to the social ${ }^{47}$ when it comes to norms making and legitimization processes and - sometimes - to the bureaucratic when it comes to complex processing of international governmental or nongovernmental organizations. Furthermore, authority has been redistributed from the national/international to the local/transnational and from state to groups and social, ethnic and even militia micro-formations. Interestingly, power does not only emerge at the hands of the new actors due to the retreat of state (Strange, 1996), the new actors also do gravitate power from its traditional holder, state; such redistribution usually occurs randomly and irregularly.

In addition to the plurality of actors and the multiplication of authority, GG is characterized by the complexity of issues, globally governed or to be globally governed. In this sense, GG implies collective processes to govern global issues on which actors show

\footnotetext{
46 In order to get an overview of how governance resources are distributed among actors. See (Weiss and Kamran, 2009:48-51).

47 The social includes the social movements that serve as transnational voices for change; transnational civil society forces generally speaking.
} 
greater patterns of interdependence; such as environmental issues, epidemics, financial crises, drug/arms trade, organized crime, terrorism, transnational corruption among others. The emergence of global issues has been accompanied by aspects of strong interdependence among the involved actors. GG actors have become ever more highly interdependent due to the increasing dispersion of governance resources among them in a way that no actor can hold and use them all together. That is what makes the "global problems need global actions" phrase relevant.

Furthermore, perhaps even more importantly, the rise of global issues has led to a contestation of the legitimacy of actors and the legitimacy of actions as well. Therefore, the ontology of GG is not - and should never be - of purely materialistic nature. Moreover, perhaps more significantly, it is of a social nature to which some IR (constructivist) scholars refer as ideational (Petrova, 2003).

GG is a "complex of formal and informal institutions, mechanisms, relationships, [networks, partnerships] and processes between and among states, markets, citizens and organizations - both intergovernmental and non-governmental - through which collective interests are articulated, rights and obligations established and differences are mediated." (Thakur and Langerhove, 2006:233) Accordingly, it is not only a matter of change in the structure of international relations and/or the international system; it is a question of the very ontology of actors within the international system; how they perceive their identities and how they define their interests and pursuit them collectively. This implies an endeavour to shift focus away from the predefined/pre-given actors' interests posited by realist IR scholars toward national identities and norms that define what the pursued interests should be, not what they are. Such a shift promises a richer picture of world politics where actors' interests are shaped by historical legacies, traditions and culture, and inter-actor relations are not exclusively guided by the interest in (individual) survival pursuit or power accumulation (Petrova, 2003:146). Non-state actors, social movements, epistemic communities, private sector actors etc., seek very different interests that are defined and pursued very differently.

Thus, international relations are no more conceived as a system of constantly sometimes violently - colliding 'billiard balls', as realist IR scholars used to claim, but as a 'cobweb' of political, economic, social, and very often hybrid relations connecting sub- 
national, national, transnational, international and supranational actors within different forms of organizations, regimes ${ }^{48}$, institutions, networks, partnerships... etc.

\subsection{Networks / Partnerships of Global Governance}

The emergence of GG networks/partnerships has come as a response to mainly two problems: firstly, as a response to what has become known as the 'democratic deficit' and/or the 'participatory gap' in GG, because citizens, social actors and even private sector actors claim that they have been increasingly excluded from policy decision-making processes that affect their interests. The 'democratic deficit' problem has obviously moved from national governance to GG sphere; secondly, as a response to the ineffectiveness and inefficiency of traditional international policy decision-making mechanisms - agreements, treaties, arrangements, international organizations and agencies... - in meeting the evercomplicating profound challenges of an increasingly globalizing and interdependent world.

Steets (2009:124) defines global governance networks/partnerships "as voluntary cooperative arrangements, involving public, private and/or civil society organizations that focus on a [global] public policy problem. Networks and partnerships can take a more or less institutionalized form." Thus, it is the degree of institutionalizedness that sets the yet slight difference between a GG network and a GG partnership. Steets (2009:124) points out that "some analysts prefer the term 'network' for more informal arrangements and 'partnership' for more strongly institutionalized forms of cooperation. The use of the concepts is, however, not consistent and while it was particularly popular to speak about 'networks' in the early stages of the debate, the current term of choice for analysts and practitioners seems to be 'partnerships'." Therefore, echoing Steets, we tend to use the two terms interchangeably.

In order to link GG networks/partnerships back to the rise of complex global issues and challenges, many of which pose critical and urgent threats on a global scale, it is argued that tackling effectively such global problems requires strategies that are made and put into action on all levels - local, national, regional and global, which turns GG into some form of complex multi-level governance. It is obvious that global institutions cannot act effectively in the absence of effective institutions on other levels, mainly speaking the national and the local. Thus, governing global public policies is essentially based on networks/partnerships among the actors involved. Networks/partnerships may include

\footnotetext{
48 A widely cited definition of international regimes is that of Krasner. He believes that a regime is a set of "implicit or explicit principles, norms, rules and decision-making procedures around which actors' expectations converge in a given area of international relations." (Krasner, 1983)
} 
individuals (activists, scientists, experts, officials...), intergovernmental organizations, nongovernmental organizations, and social movements.

The concept of networks, more significantly than that of partnerships, is based on the idea of bridging. They construct bridges between and among actors; actors that used very often to work against each other, at least from a realist perspective. They "operate by bridging the technical and administrative expertise possessed by industry actors, and the legitimacy garnered by state regulatory endorsement." (Detomasi, 2007:328) Bridges are not to be only constructed between and among actors, they are also to be constructed between and among governance sectors; that is why GG does not need to be only conceived of as multilevel, but also as multi-sectoral.

What distinguishes GG networks, as institutional innovations ${ }^{49}$, from traditional institutional arrangements are three main characteristics, interdependence, flexibility and complementarity. First, interdependence implies that no actor can address the issue at stake by itself. Multi-sectorality of GG, and thus of networks, implies building bridges on a transnational scale among the public sector, the private sector (for-profit) and the social sector (non-profit) in order to enable them to pull their diverse resources together. As Reinicke and Deng (2000:29) argue, networks "combine the voluntary energy and legitimacy of the civil-society sector with the financial muscle and interest of businesses and the enforcement and rule-making power and coordination and capacity-building skills of states and international organizations."

Second, Flexibility refers to one of the most distinctive features of GG networks vis à vis traditional international organization arrangements. "Networks come in various forms and organizational shapes that can also adjust through the process of cooperation. As a result, networks structures are evolutionary in nature, able to allow for constant learning from both successes and failures. Furthermore, their evolutionary character and flexible structure allows for openness - accommodating new players during the process and tying them into the network. In the evolution of the network, old links break and new links form as required." (Benner, Reinicke and Witte, 2002:8) Flexibility of networks also helps actors to overcome the problem of bureaucratic constraints which usually characterize traditional international organization arrangements, and therefore allows them to act faster and more efficiently.

\footnotetext{
49 GG networks are seen as innovations; simply because the lack of existing mechanisms, coupled with the urgent need for solutions to serious problems, leaves room for inventing new ones. Interestingly, Reinicke and Deng (2000:29) used the same image.
} 
Third, Complementarity implies that networks are sustained by the diversity of their constituencies. Besides, it refers to their ability "to handle this diversity of actors precisely because of the productive tensions on which they rest. As a result, networks facilitate the discussion of controversial issues and provide a conducive framework for political deliberation. At the same time, they also create the conditions for the combination and coordination of complementary resources. Networks are therefore mechanisms that facilitate the transfer and use of knowledge and other resources of various actors in the global public policymaking process." (Benner, Reinicke and Witte, 2002:8)

There are many promises the growing popularity of networks/partnerships can offer. Steets (2009:124-126) lists: creating greater operational capacity and effectiveness; generating more flexibility and efficiency; encouraging innovation; establishing a cooperative work culture in participating organizations; encouraging inter-organizational learning; and creating greater opportunities for participation and increasing the legitimacy of governance.

\subsection{Legitimacy of Global Governance}

The question of legitimacy has been receiving increasing attention in the research body on GG. However, literatures have devoted excessive attention to questions of structure, efficiency, effectiveness etc. while neglecting normative issues, among which legitimacy is one of the most challenging. For Moravcsik (2004), the question of whether "GG [is considered] democratically legitimate, or [whether it undergoes...] a 'democratic deficit' [is] one of the central questions - perhaps the central question - in contemporary world politics."

However, despite the fact that IR scholars, among many other fields of study, has been attempting to re-evaluate the concept, contestation over how to define legitimacy itself still exist. Thus, a plurality of conceptions and understandings of legitimacy has overshadowed the relevant debate(s). Lister (2003:176) contends that "although the term 'legitimacy' is often used in a number of policy contexts, it is rarely defined. [...Perhaps its] 'inherent vagueness' has been the success of the concept of legitimacy." In the same context, Suchman (1995:572) notes that many researchers employ the term, but few thave attempted to] define it. Consequently and unsurprisingly, scholars and practitioners have always tended to introduce the term as a universal and objective one.

Taking such conceptual plurality into consideration helps to understand the very consequences of (il)legitimacy. Wimmel (2009:186) notes that "legitimacy concepts formulate perceptions of whether and under what conditions certain legitimacy objects, 
such as political institutions or individual political decisions, can be assumed to be acceptable or worthy of recognition and can be justified inter-subjectively and independently of the own self." The inter-subjectivity question will be examined more closely later. For Peters, "to say that an institution etc. is legitimate is to make the judgement that it meets certain normative standards of legitimacy. It follows that to get at the substance of legitimacy (i.e. to be able to judge what is legitimate/illegitimate), we need to identify the normative standards in question." (Peters, 2013:6) Here is another aspect of legitimacy that is to be examined later, normativity.

The concept of legitimacy rests on two main sub-concepts, acceptance/compliance and normative justification. First, acceptance/compliance "is often called the 'belief in legitimacy' in the tradition of Max Weber. According to this concept, the legitimacy of [an institution,] a political system or of individual decisions is dependent on the de facto support by the citizens ${ }^{50}$." (Wimmel, 2009:186) One aspect of the oft-referred to as a legitimacy crisis is the failure in maintaining a minimal level of acceptance and/or ${ }^{51}$ compliance among the target-audience of the GG policies at issue. According to this conception, legitimacy is viewed as a social more than as a legal issue, because it may happen to consider policies legitimate as long as citizens accept and follow them even if the policies prove not to be in accordance with the existing (legal) regulations ${ }^{52}$. Second, normative justification, in contrast to acceptance which can be measured empirically through for instance opinion surveys ${ }^{53}$, is more abstract and much more (inter)subjective. It "is characterized by a subjective norm that must itself first be established and justified as a criterion for evaluation. [...] Classic examples are normative justifications of certain understandings of democracy or substantive goods, such as individual freedom or social justice, which political systems must guarantee and ensure in order to be considered legitimate." (Wimmel, 2009:187)

Since legitimacy is based on acceptance/compliance, then it could be suggested to be viewed as conceptually as well as practically different from - if not opposite to coercive tools of governance, i.e. making individuals follow rules. Therefore, legitimacy helps to ensure the target-audience's compliance, because illegitimate institutions or

\footnotetext{
${ }^{50}$ Wimmel argues that acceptance can be measured empirically, usually through attitude and opinion surveys, while compliance can be recognized in adherence to legal norms.

${ }^{51}$ It would be more expressive of legitimacy to maintain them both.

52 Wimmel (2009:186-187) states a further sub-concept, legality. However, for analytical purposes, focus is to be put only on the two most relevant ones (acceptance/compliance and normative justification).

53 Further indicators, such as protest/support movements or public debates, can be used to measure acceptance empirically.
} 
systems will certainly need to employ coercive instruments and therefore it would be even more difficult for them to function.

Buchanan and Keohane (2006:405) distinguish between the normative or philosophical and the sociological meaning of legitimacy. In their words, "to say that an institution is legitimate in the normative sense is to assert that it has the right to rule. [In contrast,] an institution is legitimate in the sociological sense when it is widely believed to have the right to rule."

Transparency is a further concept that is closely linked to legitimacy of $G G^{54}$. Seattle mass protests against globalization have increasingly brought the question into debate through what has been referred to as a crisis of legitimacy. Transparency, defined as ensuring "the right to know" 55 for the actors involved, has become more and more salient as policy making processes have become less open to the involved actors, due to the proliferation of global actors and stakeholders on the one hand, and to the increasing complexity of global issues on the other hand. Furthermore, Peters (2013:11) considers what he calls the "allaffected principle," i.e. the principle that those who are affected by a political decision should have the power to influence it. As to available literature so far, one can refer to the increasingly contentious debate on transparency and access to public policy making processes in the European Union, for instance, and in World Trade Organization as well.

\section{Legitimacy of Global Governance as a Theory}

Interestingly, the growing usage of the term GG, among scholars and policy practitioners as well, coincided with the end of the cold war, a major event that has not only changed international politics structure and processes, but has also spurred intense interest in discovering alternative approaches to international relations in post-cold-war era. Still, GG has remained highly contested, both among traditional and 'new' approaches.

For many scholars, however, the very novelty of the concept should be questioned and placed under scrutiny. According to Ba and Hoffmann,

"Whether or not scholars explicitly discuss global governance, governance has always been the center of the study of world politics-'Governance is now fashionable, but the concept is as old as human history'. All of the studies of cooperation under anarchy, all of the various (neo)realist

\footnotetext{
54 James O'Connor notes that a great many of conceptions are being invoked in attempts to 'explain' the conception of legitimacy; they include consent, authority, justice, the 'moral basis for social Interaction,' normative belief that a rule or institution must be Obeyed, popular sovereignty, democracy, and "right" or rightfulness. The list could go on. See (O’Connor, 2007:3).

55 The phrase, "the right to know," has been coined by Ed Florini (2007).
} 
treatises on balance of power, all of the analyses of regimes, and all of the English School's work with international society are at heart concerned with discerning the order that actors in world politics create and follow in an anarchical world." (Ba and Hoffmann, 2005a:3)

This could be denied only in one single case, if we set back to the traditional use(s) of the label international, ranging from international relations/politics to international - not global - governance. Significantly, Gilpin for instance entitled his contribution in a 2002 edited volume "A Realist Perspective on International Governance," (Gilpin, 2002 [emphasis in the title is added]) despite that the title of the volume used explicitly the label Global Governance, "Governing Globalization: Power, Authority, and Global Governance."

Nevertheless, many other scholars (have) tend(ed) to regard GG as new and different, as a concept, as a phenomenon and as a theory to approach post-cold-war international politics. Again, as Ba and Hoffmann (2005a:3) note, "global governance is new because of the 'global' modifier for governance" which radically challenges the traditional state-centric image of international relations and its subsequent aspects. This way, GG shifts attention from state-centeredness to a multiplicity and diversity of actors, and from inter-state relations to trans-actor networks of interactions within an increasingly complex world.

Theories of (approaches to) GG represent two main theoretical and even philosophical traditions within the field of IR. In whatever way the two traditions are articulated, they reflect the above-mentioned distinction among the critical implications of the two labels, international relations on the one hand and global governance on the other. While the concept of international relations "is by definition primarily interested in 'politics among nations' and pays rather little attention to non-state actors, the [concept of] GG does not establish such a hierarchy.” (Dingwerth and Pattberg, 2006:191)

Consistent with what has been said, Dingwerth and Pattberg (2006:192) add three further distinctions among the implications of the two labels. Firstly, while "international relations suggests that international interaction can be analyzed separately from interaction at other levels of social interaction, [...] GG conceives of world politics as a multilevel system in which local, national, regional, and global political processes are inseparably linked;" Secondly, while "international relations is traditionally linked to power relations, interest-based interstate bargaining, and, more recently, the role of norms and advocacy networks as the driving forces of politics beyond the state, [...] GG starts from the assumption that a wide variety of forms of governance exist next to each other and that a hierarchy among these various mechanisms is hard, if not impossible, to discern; [... and 
thirdly,] while research in the field of international relations tends to focus on the phenomenon of authority and its legitimation primarily in close connection with the state's ability to pursue its rational self-interest, a GG perspective allows capturing the emergence of new spheres of authority in world politics independently of sovereign nation-states." (Dingwerth and Pattberg, 2006:193)

However, such distinction reflects a broader dichotomy-based debate among two leading paradigms within the field of IR theory. Labels indeed greatly vary, and under every context, one can refer to different appellations. The debate yet remains deeply epistemological. It has been referred, earlier in this article, to Buchanan and Keohane's contrast between the normative and the sociological meaning of GG legitimacy. They argue, to spell out again, that "an institution is legitimate in the normative sense is to assert that it has the right to rule; [in contrast,] an institution is legitimate in the sociological sense when it is widely believed to have the right to rule." (Buchanan and Keohane, 2006:405) This implies, whether explicitly or implicitly, that the first meaning rests on an objective(ist) understanding, whereas the second rests rather on an inter-subjective(ist) understanding.

Following this, it could be argued that two main modes of theorizing have led to the establishment of such a dichotomy. The two modes have become well familiar to IR scholars as explanatory and constitutive theory. An explanatory theory "sees the world as something external to our theories of it. In contrast, a constitutive theory [...] thinks that our theories actually help construct the world." (Smith and Owens, 2005:273) The debate between the two can be reframed as a contestation between the theories that think of the social world as like the natural world on one hand, and the theories that see our language, our concepts and our very theories as helping (re)construct that world on the other hand. Actually, such a divide has significantly broken up IR scholarship into two divergent sorts, scholars seeking to explain and scholars seeking to constitute the social reality. Accordingly, an explainer tends to be objectivist while a constituter tends to be inter-subjectivist. At this point, it could be argued that legitimacy of GG lacks any consensus as to how it comes into practice, normatively or sociologically in the words of Buchanan and Keohane; whether it is pre-given or inter-subjectively constructed. Such an inadequately answered question remains a significant blind-spot in the literature on GG legitimacy.

More broadly, epistemological distinction has been (to be) made between ideationalist and materialist thinking concerning the foundations of GG. The ideationalistsmaterialist gap finds its origins in an earlier debate on the end of the Cold War, which was a crucial juncture for IR constructivist scholars to challenge and delegitimize the 
(neo)realist mainstream, because the latter mainly failed not only to predict but also to offer an adequate explanation to the way how the Cold War ended. Constructivists contended that (neo)realism was - and is still unable to understand change in world politics due to its excessive focus on material factors (power, military capabilities, bipolarity...) at the system level, and therefore it fails to see and then explain changes in ideational factors (ideas, perceptions, identities, meanings...) at the individual/collective and domestic level that eventually led to the transformation of the system.

(Neo)realists call upon material power and material conditions, among which power constraints and incentives are at the foremost, to explain the rules and patterns of GG. On the other hand, constructivists claim that GG is 'ideas all the way down' (Wendt, 1999). They argue that the "ideational foundations of GG cannot be ignored because in the end ideas provide the most basic foundations of governance: who participates, how actors interrelate with one another, what issues are considered important, and even how actors get what they want." (Ba and Hoffmann, 2005b:250)

Whichever the stance one may put more focus on, the two approaches are complementary; both are analytically indispensable but none is adequate by itself to offer a comprehensive understanding. For brevity, emphasis is to be placed on how the problem of legitimacy is theoretically perceived. Next, we examine how different (main) IR theories approach the very concept of GG legitimacy. Three theories are to be examined, (neo)realism, neo-institutionalism and (social) constructivism.

(Neo)realists believe that the structure of the international system is anarchic, i.e. there is no central authority to create and impose any rules of conduct. International relations are therefore "represented as a self-help, zero-sum game where states have to keep their relative position either by forming alliances, or internally, by increasing their own military and economic [power.]" (Petrova, 2003:117) Consistent with that, Mearsheimer, a prominent neorealist, defines institutions as "sets of rules that stipulate the ways in which states should cooperate and compete with each other." (Quoted in Simmons and Martin, 2002:259) He stresses the fact that states create institutions not only to cooperate but also to compete. Thus, institutions can only reflect existing patterns of power distribution among states, and they are used only as an instrument to maintain and sustain the status quo.

It is neorealists' excessive focus on relative gains that makes them under-estimate, and thus under-theorize, international institutions. For Grieco and Mearsheimer, again, the pursuit of relative-gains "prevent[s] states from intensive cooperation: since the benefits of 
cooperation can be translated into military advantages, concerns about the distribution of the gains impede substantial sustained cooperation.” (Simmons and Martin, 2002:261) The instrumentality of institutions can be better conceived of through the fact that "powerful states, in [t] his view, often have the ability to present others with a fait accompli to which they are forced to adjust, sometimes making them worse off than they were before the agreement was made." Regarding the question of legitimacy in the view of (neo)realists, it seems that GG institutions, and broader arrangements, are not independent from the states which create them and provide them with their raison d'etre and consequently with their legitimacy.

On another hand, neo-institutionalists seem to be more optimistic about international institutions s $^{56}$ a "a way for states to overcome problems of collective action, high transactions costs and information deficits or asymmetries." (Simmons and Martin, 2002:261) They argue that,

"[...] institutions would be effective to the degree that they allowed states to avoid shortterm temptations to renege, thus realizing available mutual benefits. In particular, institutions could help to focus expectations on a cooperative solution, reduce transaction costs and provide a greater degree of transparency, through which it was expected that reputational concerns would come into play, thus rendering cooperative rules effective. In short, institutions could be explained as a solution to the problem of international collective action, providing a response to the puzzle posed by realism." (Simmons and Martin, 2002:262-263)

Additionally, the institutionalization of international relations has been driven by states' interest in reducing what Lake called "the risk of opportunism and governance costs;" the risk of opportunism generally decreases as the level of hierarchy in an institution increases, whereas governance costs increase as the level of hierarchy increases. Acting rationally, states choose an institution that balances these two dynamics.

In addition to their rigorous work on international issue-specific regimes, neoinstitutionalists have widely contributed to the establishment of a conception of GG as an effective way to create inclusive networks to govern global issues even in the absence of anything similar to a world government. However, in contrast to (neo)realist conception of the full dependence of international institutions on state(s) power, institutions/regimes, in order to operate, require sets of rules and norms most of which are of social nature.

\footnotetext{
${ }_{56} \mathrm{Neo}$-institutionalists more often use the term international regimes as interchangeably with international institutions.
} 
Casting more light on non-state actors, neo-institutionalists believe that GG can play an independent role from states. The logic of such independence draws from the idea that they are relatively "capable of encroaching upon the sovereign rights of individual states that are members of the international community and, by extension, upon the rights of individuals residing in such states, without their specific consent." (Srivastava, 2007:5) In this view, legitimacy of GG institutions is not derived only from states, but also from the broader wide-range of GG actors.

On another end of the spectrum, and more interestingly, we find (social) constructivists. While neo-instirtutionalists have hopefully believed in promoting cooperation under anarchy, social constructivists have tended to question the very ontology of anarchy itself. Drawing from their label, (social) constructivists contend that anarchy is not pre-given, but rather socially constructed.

Constructivists define institutions in a wider sense than that of neo-institutionalists. Drawing from English School's insights, constructivists view institutions as "cluster[s] of social rules, conventions, usages, and practices ..., $[\ldots]$ set $[\mathrm{s}]$ of conventional assumptions held prevalently among society-members ... [that] provide a framework for identifying what is the done thing and what is not in the appropriate circumstances." (Simmons and Martin, 2002:266)

More importantly, constructivists argue that institutions and actors' identities, since considered as ideational more than material subjects, are of a mutually constitutive nature. They assert that "international institutions define who the players are in a particular situation and how they define their roles, and thus place constraints on behavior. [Furthermore, they] emphasize that international institutions can alter the identities and interests of states, as a result of their interactions over time within the auspices of a set of rules." (Simmons and Martin, 2002:267)

Accordingly, legitimacy of international institutions, and of GG by extension, is of no exception within constructivism. It is rather socially-constructed and of a constitutive and inter-subjective nature. A GG institution, arrangement, network, etc. is not considered fully legitimate if it lacks that belief in its legitimacy among the actors involved and affected by its processes. Such belief, without doubt, is of a social nature; it is socially and intersubjectively constructed among them. Understood in this way, legitimacy becomes a very dynamic process. It is not given but constituted, not earned once but accumulated continuously through a complex fluctuating process of evolution and dissipation. 
Drawing on what precedes, it seems that GG as a theory tends more significantly to self-introduce as a nontraditional way of thinking in IR field, opposite more or less to statecentric and materialist approaches as it has been discussed above. However, has such a selfintroduction been widely acknowledged among the field's scholarship? In fact, it has been still struggling for paradigmatic recognition within a field that still seems well-establishedly dominated by traditional paradigm(s). As $\mathrm{Ba}$ and Hoffmann (2005a:6) put it, "traditional/established international-relations theory, in its readiness to adopt a 'politics as usual' view of world developments, has a tendency to dismiss GG/challenger approaches as something akin to "peace studies"- naïve, misguided, or at least an example of wishful thinking."

Among many IR scholars, the view that international relations, world politics or even GG are essentially state-centered still gains as much legitimacy as the view that GG remains a state-dominated system does. They seem "ready not to dismiss the state, but to remove it from its accustomed pedestal." O’Brien, for instance, although "gives priority to non-state actors in [an] exposition on global civil society, but he also admits that often times, global civil society actors are reactive-reacting to the actions and systemic rules set up by the state." (Ba and Hoffmann, 2005b:256) Even the plurality of actors has been questioned. Overbeek (2005:39-40) on another hand argues that plurality of actors, interests and structures or spheres of authority, using Rosenau's terminology, is not the essence of things. He denies such plurality to be as essentially undetermined, unbiased and neutral; he rather draws much more attention towards seeing this plurality as set in a wider hierarchical configuration of social [as well as material] power. In this sense, "being aware of [not so] new actors does not necessarily translate into seeing an increased role for them in the governing of world affairs.” (Ba and Hoffmann, 2005b:256)

\section{Legitimacy of Global Governance as a Practice}

Having questioned the legitimacy of GG as a theory throughout the preceding section, we now move to question its very legitimacy as a practice. At a certain point of analysis, it would be concluded that theoretical and conceptual implications cannot be detached from practice questions that address how GG is being done. However, such a context of analysis is not, at all, free of normative premises and conclusions as well. More than a decade ago, Murphy and Wilkinson well framed this tough marriage among GG practice(s) and the question of normativity. They, participating in the 2001 GG Workshop at the University of 
Delaware, asked: "in whose interests is GG being pursued?" ( $\mathrm{Ba}$ and Hoffmann, 2005b:262) This is just one, widely cited, example to illustrate the case.

In the current section, we attempt to develop two main argumentations. First, we argue that GG is not so global, and that world politics has witnessed not the rise of GG, but $a$ rise of many not so GGs, this argument echoes Rosenau's claim that GG is increasingly structured differently in different parts of the world and in different issue areas, resulting in "a plethora of governances;" (Rosenau, 2009:1) and second, we argue that although GG still undergoes a democratic deficit, debate on its legitimacy needs to go beyond the traditional lines around which the democratic deficit problematique is usually discussed, such a debate-strategy is suggested as a way out of the problematique.

\subsection{First: Is global governance so global?}

At issue here, in particular, is what Dingwerth and Pattberg (2009) call 'the geographical bias' of GG. It can be argued that 'the geographical bias' of GG as a practice is more critical. The way how GG is (being) done, to put it differently, actually makes it not accurately global in the literal sense.

The term of GG, as it has been widely used, misleadingly implies a certain degree of homogeneity of governance processes and structures on the global level. Nevertheless, one cannot deny, not without difficulty, that "beyond the OECD world, in which the dense integration of politics, law, economy, and civil society and the frequent transboundary interlinkages constitutes a post-national system of politics, the 'new second world' of EU enlargement candidates and a few (South) East Asian societies can also be considered as capable of actively and passively participating in GG." (Dingwerth and Pattberg 2009:60) Dingwerth and Pattberg, borrowing from Senghaas's work, argue that,

"[...] this is very different for the 'third' and 'fourth world'. In the third world, the centres are integrated, if only asymmetrically, in the transnational club of the first and second world, while the periphery is structurally dependent on its own centres and hence incapable of effectively participating in transboundary, let alone global, governance. Finally, in the fourth world, societies no longer dispose of regulatory capacities because the state has either failed or been usurped by private actors. On this account, the necessary preconditions for effective governance through the pooling of complementary resources are virtually absent in large parts of the world, thus making GG a much less global affair than the label might suggest." (Dingwerth and Pattberg 2009:60-61)

This intervention brings into discussion the problem of representation, on which much debates on GG legitimacy rest. Numbers in this regard can help to illustrate, for 
instance, the fact that the largest numbers of non-state actors, non-governmental organizations and multinational businesses mainly speaking, come from a limited sphere of the globe, which undermines the globalness of GG.

This argumentation draws on the example of the WTO-NGOs' nexus. In 1996, the WTO General Council devised Guidelines that ascertain that the organization's secretariat would establish a space for recommendation exchange between the members of the organization and the NGOs involved. In fact, the rationale of these Guidelines has been to contribute to increasing public awareness about the organization's activities, looking for wider acceptance of its activities and augmenting its legitimacy.

Projected patterns of NGOs' participation in WTO, as a GG network, include among others (Srivastava, 2007:18-19): participation in the Ministerial conferences; participation in issue-specific/general symposia; participation in WTO Secretariat's regular briefings; and submission of papers on specific issues. However, the actual practice patterns have evidently asserted the idea that developing countries' NGOs are significantly under-represented in WTO. The resources factor is certainly very relevant in this context. The under-representation of a large part of the globe affected by the WTO processes, however, casts increasing doubts over the question of its legitimacy and brings the inclusion/exclusion issue into question.

The graphs in the Annex show how developed countries-based NGOs have overwhelmingly dominated the WTO successive ministerial conferences, from Seattle (1999) to Bali (2013). The graphs have been prepared drawing on statistics available on W'TO's official website, http://www.wto.org/index.htm.

Cancùn Ministerial Conference, just to remark, witnessed a seemingly significant number of 33 NGOs coming from Mexico and 18 NGOs coming from Brazil. Such a noteworthy increase in developing countries-based NGOs presence was not as significant as it may appear, as it could be simply explained through the fact that the Ministerial Conference was hosted in Cancun, Mexico. However, it is evident that NGOs from the U.S., the U.K., Canada, and France, Belgium, Switzerland just to name some, have continued to dominate.

Reinicke and Deng (2000: xvii-xviii) bring into light what they consider as a "dual challenge of inclusion." They question the widely believe in the claim that political liberalization and technological change have made it far easier than before for people all over the globe to be connected with each other, as inclusion of all interested people in a network's activities remains far difficult. In this sense, GG networks have been facing a 
dual challenge of 'local-global' and 'North-South' inclusion, that is, to bring local involved actors into the global dialogue and to bring stakeholders in developing countries into a process that tends to be dominated by developed countries stakeholders.

There is a further aspect of GG practice that can be discussed in order to argue against its globalness. GG networks are characterized by being multi-sector and specificissue structured, i.e., scholars and practitioners, explicitly or implicitly, consider not one GG but many GGs, such as global environmental governance, global economic governance, global health governance, etc. This has been a practical necessity, mainly due to the increasing complexity of global affairs and the multiplicity of the actors involved, but at the same time it poses serious challenges to the issue of legitimacy.

It is important, analytically, not to consider GG processes as unitary as the term itself suggests. Distinction among the various sector-based global policies and among specific issue-based processes should be always brought into mind. Accordingly, GG legitimacy as well as effectiveness need to be reconsidered per sector and per issue in order to avoid jumping to false absolutist conclusions. To put in differently and more conceivably, GG mechanisms are expected to show higher vulnerability to legitimacy deficits, and even to performance failures, in just certain sectors and/or specific issues. Thus, claims of effectiveness/efficiency and public legitimacy should not be dismissed as long as certain issues prove to be ungovernable - or hard to be governed. Similarly, criticisms of the overall system of GG should not be taken too seriously, as GG mechanisms prove to be efficient problem-solvers when it comes to many different issues.

However, it seems that the current body of literature on issue-based GG lacks some kind of theoretical equity when it comes to setting qualitative distinction among the various processes and structures that fall within the purview of GG. As Dingwerth and Pattberg put it (2009:61), although the sectors and issues effectively/efficiently regulated through GG processes are very adequately - and to a large extent satisfactorily - theorized, the current literature nonetheless imply some kind of under-theorization when it comes to the ungoverned - or even ungovernable - sectors and issues where regulation is completely or even partially absent. If GG is based on the dual rationale of promoting global goods and decreasing global bads, it would be evident that a wide range of bads are still out of GG networks control, and a variety of actors do not seem as willing to interact and exchange governance resources with other actors in order to pursue their political ends through GG channels; instead they sometimes act individually not collectively, using less globally desired means such as violence, direct action, or ad hoc coalitions. 
Finally and more importantly, the ways in which GG is (being) done may represent a challenge to its very globalness. Rosenau (2009:11) noted that no single organizing principle on which GG rests does exist and no order around which communities and nations are likely to converge has emerged. So, what is referred to as GG is in fact the sum of myriad control mechanisms driven by different histories, goals, structures, and processes, and every mechanism shares a history, culture, and structure with a few others; and eventually no characteristics or attributes common to all mechanisms do exist. This would prove to be very profoundly relevant when it comes to the assessment of GG dynamics and processes. Again, diversity of governance traditions among geographies, histories, cultures power structures if to be taken into serious consideration invites scholars to rethink GG un-globally.

\subsection{Second: Is 'democratic deficit' all what hinders $G G$ from being legitimate?}

It has been usually tended to define GG legitimacy through what has become well known as the 'democratic deficit.' Even the emergence of GG networks/partnerships has typically been conceived of as a response to the 'democratic deficit' and/or the 'participatory gap' in GG, because citizens, social actors and even private sector actors claim that they have been increasingly excluded from policy decision-making processes that affects their interests. In this way, the 'democratic deficit' problem seems as it has moved from national governance to GG domain(s). In this context, Moravcsik (2004) argued that the question of whether "GG [is considered] democratically legitimate, or [whether it undergoes...] a 'democratic deficit' [is] one of the central questions - perhaps the central question - in contemporary world politics." Accordingly, it can be concluded that the debate on legitimacy of GG has not gone further than a debate on the 'democratic deficit' in global policy-making - processes and structures. The two debates have become so interlinked particularly since Seattle's mass protests and the subsequent claims against undemocratic globalization and its un-democratic, un-legitimate and un-transparent institutions.

In what follows, we discuss the shortcomings of the mainstream discourse which introduces legitimacy as equivalent to democracy and therefore conceives of the crisis of legitimacy of GG institutions as an outcome of being processing undemocratically, i. e. as an outcome of not meeting liberal democracy standards. In simpler words, for GG 
institutions, to be legitimate is to be democratic ${ }^{57}$. Apparently, this common view rests on what has been discussed earlier about the origins of the emergent crisis of GG legitimacy; that policy making processes on a global scale have become less and less open to the actors involved, due to the proliferation of actors and stakeholders on the one hand, and to the increasing complexity of global issues subject to GG on the other hand. Such developments have significantly undermined the 'the right to know' for the actors involved and put what Peters called the 'all-affected principle' out of action. It has been widely claimed that legitimacy of GG mechanisms depends heavily on their ability to ensure participation, or at least representation, for people whose interests are affected by their policies.

However, such a discourse needs to be reconsidered more closely. We make great use of Peters' work (2013) and Gadinger's (2013) commentaries on it. Why legitimacy should not be - and is not - equivalent to (liberal) democracy? This question will hopefully be answered in three points.

First, legitimacy and democracy are highly contested normative concepts. However, the mainstream discourse introduces democracy in GG as a taken-for-granted universal concept referring almost always to liberal (western) experience. In this way, it seems that relevant debates are more likely to set back to the normativity dilemma, as the bistoric Western concept/experience of (liberal) democracy is always pre-given as a normative reference. However, if democracy is historic, and this is not the case, it cannot be pre-given and inserted in different historic contexts. It has been argued above in a different section that the normative is inter-subjectively (socially) constructed not objectively pre-given. Surprisingly, the mainstream discourse may widely question the normative dimension(s) of legitimacy while maintaining a non-normativist stance towards democracy.

Second, democracy is a nation-state based concept of governance, even in terms of practice; it has been always understood as a state-people less sophisticated complex, less sophisticated in comparison to doing governance beyond the state-people complex, regionally and/or globally. Thus, when it comes to debating democracy in GG, uncertainty rises as to which elements of nation-state based democracy are to be practiced on the global level. In fact, a variety of even contending approaches demonstrates that "the concept of democracy is not without its own ambiguities when it comes to conceptual and

\footnotetext{
57 Peters cites some examples of this trend. Bodansky (1999:612): "in the modern world, democracy has become the hallmark of legitimate government;" Archibugi, Koenig-Archibugi, and Marchetti (2012:2): "democracy has become widely, albeit not universally, accepted as the only way to legitimize political power." See (Peters, 2013:10)
} 
institutional implications. The more abstract the democratic principles evoked, the more vague their institutional implications. And the more concrete the democratic institutions to be transferred, the more problematic their transferability." (Peters, 2013:12) In this view, two problematic questions can be raised here: the question of how to adjust GG institutions so that they become comparable to national governance institutions, and, following from the foregoing, the question of whether it is even possible for democracy to be transferred from the national to the global level. Peters (2013:12), more importantly to the second question, challenges the transferability claims through bringing into debate the concept of the demos, as "some argue that democracy requires a more or less integrated community, a demos, and that this does not exist at the international level, making the creation of truly democratic international institutions difficult."

Third, the mainstream discourse suggests implicitly that the more democratic - and therefore the more legitimate - domestic systems of governance are; the more democratic - and therefore the more legitimate - global systems of governance become, since legitimacy of GG is but the sum of the legitimacies of domestic governances. That is why some voices still argue explicitly that concerns about legitimacy are of little importance, because as long as states participated in international agreements on a voluntary basis, no state would be obliged to do anything at the international level to which it had not consented.

Thus, "legitimacy would be guaranteed via a combination of state consensus and the operations of domestic institutions, given that states would only enter into forms of cooperation that had been legitimized domestically." (Peters, 2013:9) However, such a view is purely inter-governmentalist on one hand and liberal-democratic-centrist on the other; as it implies the exclusion of non-democratic states whose actions are therefore considered non-legitimate. Besides, other scholars, Peters is one among them, have argued that intergovernmental governance processes have extended without guaranteeing adequate involvement of parliaments or the public at large, which has resulted in making traditional forms of international cooperation inadequate to operate democracy standards, and thus turning them into a threat to democracy itself. This threat, as noted by Peters, is "argued to result either from the self-interested actions of governments themselves as they sought to weaken domestic constraints on their freedom of action or from the inherent dynamics of international institutions." (Peters, 2013:9)

Finally, it would be synthetic for the above-discussed argumentation to briefly review the Peters-Gadinger exchange about the problematique (Peters, 2013; Gadinger, 
2013). Peters has brought into attention some kind of 'labour division' among privileged 'philosophers/thinkers on legitimacy' on the one hand, and marginalized 'sociologists/researchers on legitimacy' on the other hand. Interestingly, for Gadinger, such a division evokes the old - but ongoing debate on the main purpose of political philosophy and, following from this, the appropriate research methodologies to be used in Political Science generally, and in IR particularly. The broader division in Political Philosophy has been among Platonists, "who focus on normative conceptions of a good and just world and seek out universalist standards based on pure reason, and Aristotelians [later known as Pragmatists], who deny the existence of eternally valid norms based on pure reason and instead stress the historicity, contingency, and situational nature of all human action;" (Gadinger, 2013:18) and so far, the pragmatist Aristotelians have been usually widelymarginalized despite that their emphasis has been on 'real politics' and on people's everyday problems and practices, that is on the Is rather than on the Ought to Be.

Relevantly to the subject of legitimacy, Peters (Peters, 2013:10) has made a case for a sociologically rather than philosophically oriented research programme to study legitimacy, which requires scholars to look beyond the misleading ahistoricity of Western (liberal) democracy, which requires them to "listen to the actors involved and find ways of reconstructing what they believe constitutes legitimate and illegitimate, just and unjust rule." 58 Taking the mainstream discourse, this would seem ground-breaking, as the ahictoricity of democracy, and of legitimacy therefore, if assume, would abort any "attempt to analyze the legitimacy-related issues in GG in terms of the concerns of the actors involved. Instead, civil-society protests and the like tend to be evoked only as a way of highlighting the significance of the problem," something which is doubtlessly done in vein.

There is one final, but not the last, conception to spell out again and to end with, that is inter-subjectivity. How can we re-introduce the meaning of legitimacy as intersubjective, not pre-given, drawing from Peters' contribution? Legitimacy as an intersubjective practice suggests an emancipatory move from ready-made concepts and standards however universal, objective and ahistoric they are alleged to be. For an institution, to be legitimate is to effectively and continuously engage the actors involved in (inter-subjectively) constructing its legitimacy (standards). It should be all about the actors involved themselves, how they conceive of legitimacy and how they hope it to be practiced. Primarily, it may be expressed in a plurality and diversity of ways; but inclusive traditions of

\footnotetext{
58 Peters (2013:14) suggests several ways to do this, to conduct interviews and put the question directly to the actors or, for instance, to analyse discourse and practice in legitimation and contestation.
} 
communication and interaction among the actors, as subjects of GG processes, would eventually facilitate the construction of inter-subjective meaning(s).

\section{Synthesis: Global Governance concept in the daily language of scholars and practitioners}

In an oft-quoted article, Finkelstein (1995:368) wrote, "we say [global] governance because we don't really know what to call what is going on." This depiction should not be disappointing. Quite the opposite, it should engage us in a precautionary endeavour to talk GG right so that the concept's use does not become over-popularized, under-appraised, and therefore loses its analytical as well as empirical value. GG still faces the threat of degrading to an empty expression people use meaninglessly. Many have argued that despite the remarkably increase in the use of the term both in academic and in policy making circles. A number of authors remain cautious about it and argue that international politics has not significantly changed, and ultimately, perceive of the GG talk as misleading (Dingwerth and Pattberg, 2009).

As to traditional vs. new conceptions dichotomy, one should maintain an equal distance from both. It is absolutely undeniable that the international scene has - to some extent radically - changed, but many more traditional features are still resisting the prevailing dynamics of change, which at the end should not be dismissed just to make a view point. When it comes to IR scholars, it is important to see the world they study as increasingly being predominated by regulatory international institutions, regimes, GG networks/partnerships aiming at coping with complex transnational problems; however, it is no less important for them to see the same world as still consists of some numerous geographic areas as well as policy areas under-regulated or even unregulated.

Such areas have demonstrated that networks of global good governance are unable to prevail worldwide, because the actors involved - state, sub-state, and supra-state - have not been willing to legitimize them. One can point out many cases, as to policy areas: climate change, $\mathrm{CO}_{2}$ emissions, nuclear weapons proliferation, humanitarian intervention, etc.; and as to geographic areas: Middle East and Sahel. In his commentary on Peters, Gadinger (2013:22) notes that issues such as "the financial crisis, the climate-change summit, and the international negotiations regarding potential intervention in, say, Libya or Syria constitute normative discourses involving an irreducible plurality of moral standards from the economic, political, public, and private spheres." However, morally contested, complex situations as such, which undergo conflicting claims of legitimacy, "cannot be resolved 
through rational generalization or truth-seeking. These are cases where politicians, environmentalists, financial analysts, human-rights activists, and ordinary citizens disagree as to what is the most important common good."

What has been referred to as the historicity of concepts and experiences should be always made relevant for the sake of the appropriate usage of terms, concepts and discourses. We argue that GG should not be dismissed from our daily language claiming that its institutions, networks and mechanisms in general are ineffective and illegitimate, that a wide range of global serious threats/issues are not globally governed, and that GG is geographically biased (the list of claims goes on); however, when used in our daily language, GG should not be taken for granted de-contextually. Two cases can be illustrated in this regard. First, Peters (2013:9) has pointed out to some voices in the current literature which tend explicitly to undermine the importance of the rising concerns about legitimacy of GG. They argue that as long as states participated in international agreements on a voluntary basis, no state would be obliged to do anything at the international level to which it had not consented. Thus, "legitimacy would be guaranteed via a combination of state consensus and the operations of domestic institutions, given that states would only enter into forms of cooperation that had been legitimized domestically." Nevertheless, this claim would prove even poorer if de-contextualized; that is, the claim would be seen sustainable only from a pure inter-governmentalist perspective or from a liberal-democratic-centrist perspective. The question is what about non-governmental aspects of international politics and what about states in which undemocratic/totalitarian regimes rule. Second, briefly, governance - as a mode of governing beyond government - usually referred to as the "development of governing styles in which boundaries between public and private sectors have become blurred." (Pattberg, 2006:4) The question, however, is again what about economic contexts where it is not a matter of eroding boundaries between the public and the private, but a matter of the public's erosion and the private structurally predominance. Contextuality is at the very issue here.

This section concludes with Finkelstein (1995:368) once again. He wrote in the same above-mentioned oft-quoted article that " global governance' appears to be virtually anything." This is not - and should not be - a definitive fate to GG's use, and it can be firmly argued that the ongoing contestation even over the very definition of GG and how it 
should be used, in both scholars and practitioners' daily language, is doubtlessly healthy for the concept $\mathrm{t}^{59}$.

\section{Conclusion: Normativity matters!}

Bringing normativity back is very critical to the question of legitimacy. It is all about how to re-think legitimacy sociologically rather than philosophically or pure-theoretically; it is to take social contexts and inter-subjective meanings instead of abistoricizing the concept; it is, as stated earlier, to listen attentively to GG - directly affected - actors and consider what they believe to constitute the legitimate and the illegitimate; It is all about the actors involved themselves, how they conceive of legitimacy and how they hope it to be practiced.

However, to say that normativity is to re-emphasize the actors involved does not mean, in any way, to set them as the central unit of analysis. Instead, the central unit of analysis "would be the conditions for social activity (e.g., norms and rules) rather than actors and relations between them." (Dingwerth and Pattberg, 2006:199) Brown, reflecting on the concept of international regimes, considered the actors' expectations convergence around the principles, norms, rules and decision-making procedures within an international regime $^{60}$ - and therefore in any GG mechanism - as "the heart of the matter." (Brown, 2005:130) Moreover, to bring normativity back to GG conception is to turn GG into a political project rather than a research project. As stated in the Study Commission's report — "Globalization of the World Economy: Challenges and Answers" - of the German Bundestag states, "as the world becomes increasingly globalized and economic activities grow beyond national regulatory frameworks, it becomes more necessary to politically shape economic, social and environmental processes on a global scale." (Dingwerth and Pattberg, 2006:194) Politicizing GG, to put it simpler, is to engage the actors involved and re-value their activities, of all types, political, social, communicative, epistemic, etc. to get a - if not the central position within GG processing. Such a project needs to be brought into action because, as it has concluded to, the actors involved are the courses of GG's legitimacy. The project although seems to be long-term, perhaps exhaustive, but still hopeable. One can point out to the European Union's shining experience as a source for hope.

Nevertheless, such optimism should not overwhelm certain criticisms which tend to illuminate some limitations; it should not be "overload[ed] with too many expectations."

\footnotetext{
59 Pattberg (2006: 9) adopts the "interpretation of the GG discourse as an essentially pragmatic undertaking that derives its success and durability from its relative vagueness."

${ }^{60}$ Brown's discussion rests on Krasner's definition of an international regime as set of "implicit or explicit principles, norms, rules and decision-making procedures around which actors' expectations converge in a given area of international relations.
} 
(Pattberg, 2006: 18) Certainly, a politicization discourse would be double-edged. Normativity implies a set of how-questions which are answered prescriptively; in the case of GG, the how-questions start by how it is image-ined, how it is legitimized and ends unexclusively at how it is practiced, i.e. how global challenges are to be met globally. Following this, the project can express either a normative perspective on how global institutions and networks should work or a conservative hegemonic discourse on how not to change the status quo power (im)balance. Many scholars "argu[e] that GG is not a valuefree term, but rather a highly politicized concept in the midst of a discursive struggle about who decides what for whom." (Dingwerth and Pattberg, 2006:196) IR critical-theoryinspired debates are still relevant in this regard. 


\section{References}

Alkoby, Asher. 2008. "Global Networks and International Environmental Lawmaking: A Discourse Approach." Chicago Journal of International Law. 8(2): 377-407.

Ba, Alice D. and Hoffmann, Matthew J. 2005a. "Introduction: Coherence and Contestation." in Ba, Alice D. and Hoffmann, Matthew J. (eds.) Contending Perspectives on Global Governance: Coherence, contestation and world order. New York: Routledge.

Ba, Alice D. and Hoffmann, Matthew J. 2005b. "Contending Perspectives on Global Governance: Dialogue and Debate." in Ba, Alice D. and Hoffmann, Matthew J. (eds.) Contending Perspectives on Global Governance: Coherence, contestation and world order. New York: Routledge.

Baylis, John and Smith, Steve. 2005. "Introduction." in Baylis, John and Smith, Steve (eds.) The Globalization of World Politics: An Introduction to International Relations. New York: Oxford University Press, Third Edition.

Benner, Thorsten; Reinicke, Wolfgang H. and Witte, Jan Martin. 2004. "Multisectoral Networks in Global Governance: Towards a Pluralistic System of Accountability." Government and Opposition, Oxford: Blackwell Publishing.

Benner, Thorsten; Reinicke, Wolfgang H. and Witte, Jan Martin. 2002. "Shaping Globalization: The Role of Global Public Policy Networks." published in: Bertelsmann Foundation (eds.) Transparency: A Basis for Responsibility and Cooperation. Gütersloh: Bertelsmann Foundation Publishers.

Brown, Chris. 2005. Understanding international relations. UK: Palgrave Macmillan, 3rd Edition.

Buchanan, Allen. 2011. "Reciprocal Legitimation: Reframing the Problem of International Legitimacy." Politics, Philosophy \& Economics. 10(1): 5-19.

Buchanan, Allen and Keohane, Robert O. 2006. "The Legitimacy of Global Governance Institutions." Ethic and International Affairs. 20(4): 405-437.

Detomasi, David Antony. 2007. "The Multinational Corporation and Global Governance: Modelling Global Public Policy Networks.” Journal of Business Ethics. vol. 71: 321-334.

Dingwerth, Klaus and Pattberg, Philipp. 2009. "Actors, Arenas, and Issues in Global Governance." in Whitman, Jim (ed.) Palgrave Advances in Global Governance. New York: Palgrave Macmillan.

Dingwerth, Klaus and Pattberg, Philipp. 2006. "Global Governance as a Perspective on World Politics." Global Governance. 12: 185-203.

Finkelstein, Lawrence S. 1995. "What Is Global Governance?” Global Governance. 1(3): 367372. 
Gadinger, Frank. 2013. “Don't Be Afraid to Get Your Hands Dirty: The Case for Researching Everyday Legitimacy." Global Cooperation Research Papers 2. Centre for Global Cooperation Research (KHK/GCR21).

Lederer, Markus and Müller, Philipp S. 2005. Criticizing Global Governance. New York: Palgrave Macmillan.

Lister, Sarah. 2003. "NGO Legitimacy: Technical Issue or Social Construct?" Critique of Anthropology. 23(2): 175-192.

Moravcsik, Andrew. 2004. "Is there a 'Democratic Deficit' in World Politics? A Framework for Analysis." Government and Opposition. 39(2): 336-63.

Mayntz, Renate. 2010. "Legitimacy and Compliance in Transnational Governance." MPIfG Working Paper 10/5. Max-Planck-Institut für Gesellschaftsforschung, Koln.

Overbeek, Henk. 2005. "Global Governance, Class, Hegemony: A historical Materialist Perspective." in Ba, Alice D. and Hoffmann, Matthew J. (eds.) Contending Perspectives on Global Governance: Coherence, contestation and world order. New York: Routledge.

Pattberg, Philipp. 2006. "Global Governance: Reconstructing a Contested Social Science Concept.” GARNET Working Paper. No 04/06.

Peters, Dirk. 2013. "Rethinking the Legitimacy of Global Governance: On the Need for Sociological Research and Philosophical Foundations." Global Cooperation Research Papers 2. Centre for Global Cooperation Research (KHK/GCR21).

Petrova, Margarita H. 2003. "The End of the Cold War: a Battle or Bridging Ground between Rationalist and Ideational Approaches in International Relations?" European Journal of International Relations. 9(1): 115-163.

Reinicke, Wolfgang and Deng, Francis. 2000. Critical Choices: The United Nations, Networks, and the Future of Global Governance. Ottawa: International Development Research Center.

Rosenau, James N. 2009. "Global Governance or Global Governances?” in Whitman, Jim (ed.) Palgrave Advances in Global Governance. New York: Palgrave Macmillan.

Rosenau, James N. 2006. The Study of World Politics. Volume 2: Globalization and Governance. New York: Routledge.

Rosenau, James N. 1990. Turbulence in World Politics: A Theory of Change and Continuity. US: Princeton University Press.

Smith, Steve and Owens, Patricia. 2005. "Alternative Approached to International Theory." in Baylis, John and Smith, Steve (eds.) The Globalization of World Politics: An Introduction to International Relations. New York: Oxford University Press, Third Edition.

Steets, Julia. 2009. "Global Governance as Public Policy Networks and Partnerships.” in Whitman, Jim (ed.) Palgrave Advances in Global Governance. New York: Palgrave Macmillan. 
Strange, Susan. 1996. The Retreat of the State: The Diffusion of Power in the World Economy. Cambridge: Cambridge University Press.

Srivastava, Jayati. 2007. "Legitimacy and Global Governance Institutions: Challenges and Possibilities from the WTO's Experience." Paper Presented at the Conference on "Pathways to Legitimacy? The Future of Global and Regional Governance," 10th Anniversary of CSGR, 2nd Annual Meeting of GARNET, University of Warwick, 2007.

Thakur, Ramesh and Langerhove, Luk Van. 2006. "Enhancing Global Governance through Regional Integration." Global Governance. 12(3): 233-240.

Weiss, Thomas G. and Kamran, Annelies Z. 2009. "Global Governance as International Organization." in Whitman, Jim (ed.) Palgrave Advances in Global Governance. New York: Palgrave Macmillan.

Wimmel, Andreas. 2009. "Theorizing the Democratic Legitimacy of European Governance: a Labyrinth with No Exit?” European Integration. 31(2): 181-199.

Witte, Jan Martin; Reinicke, Wolfgang H. and Benner, Thorsten. 2000. "Beyond Multilateralism: Global Public Policy Networks.” International Politics and Society. 2/2000. 


\section{Appendix}

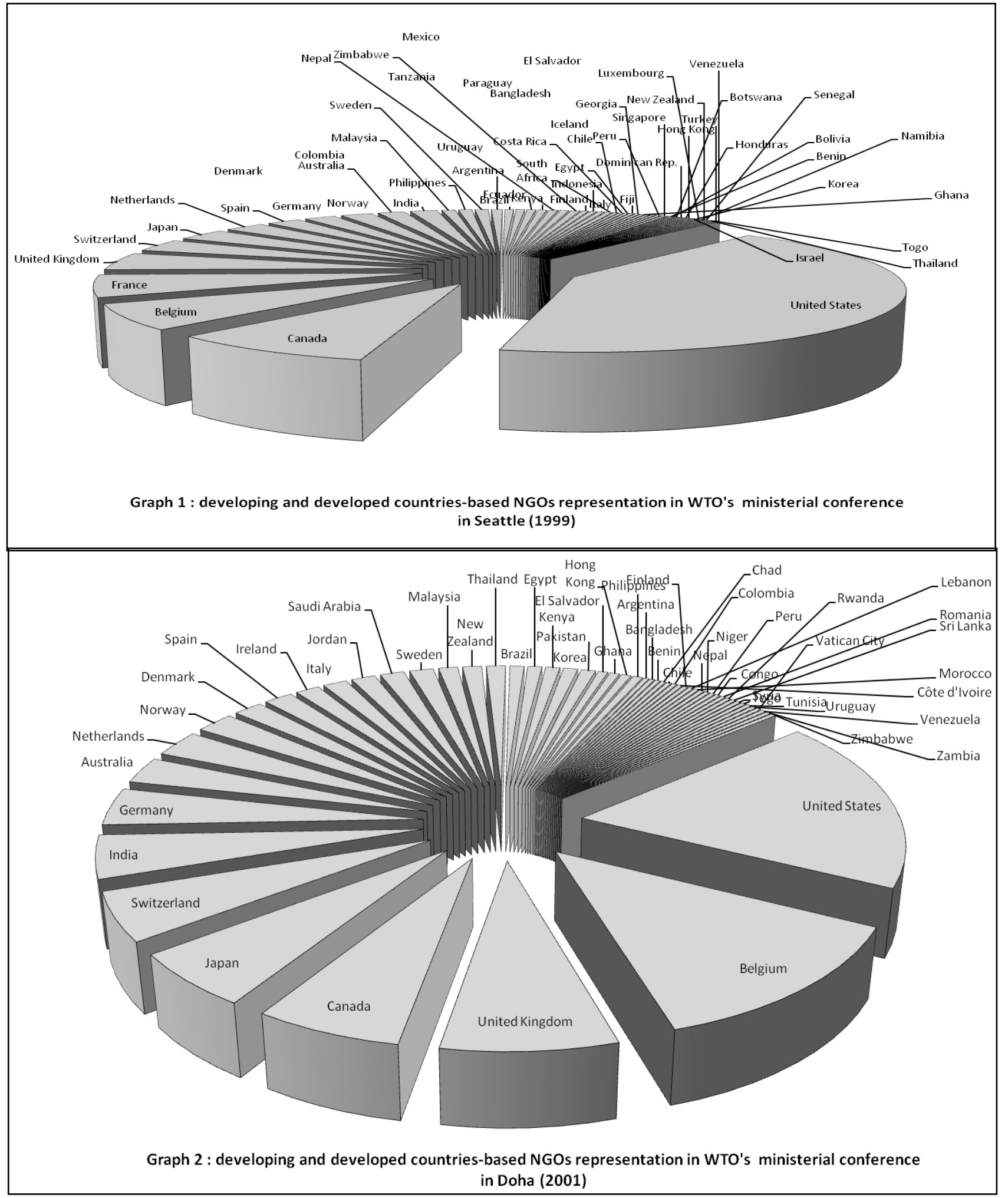




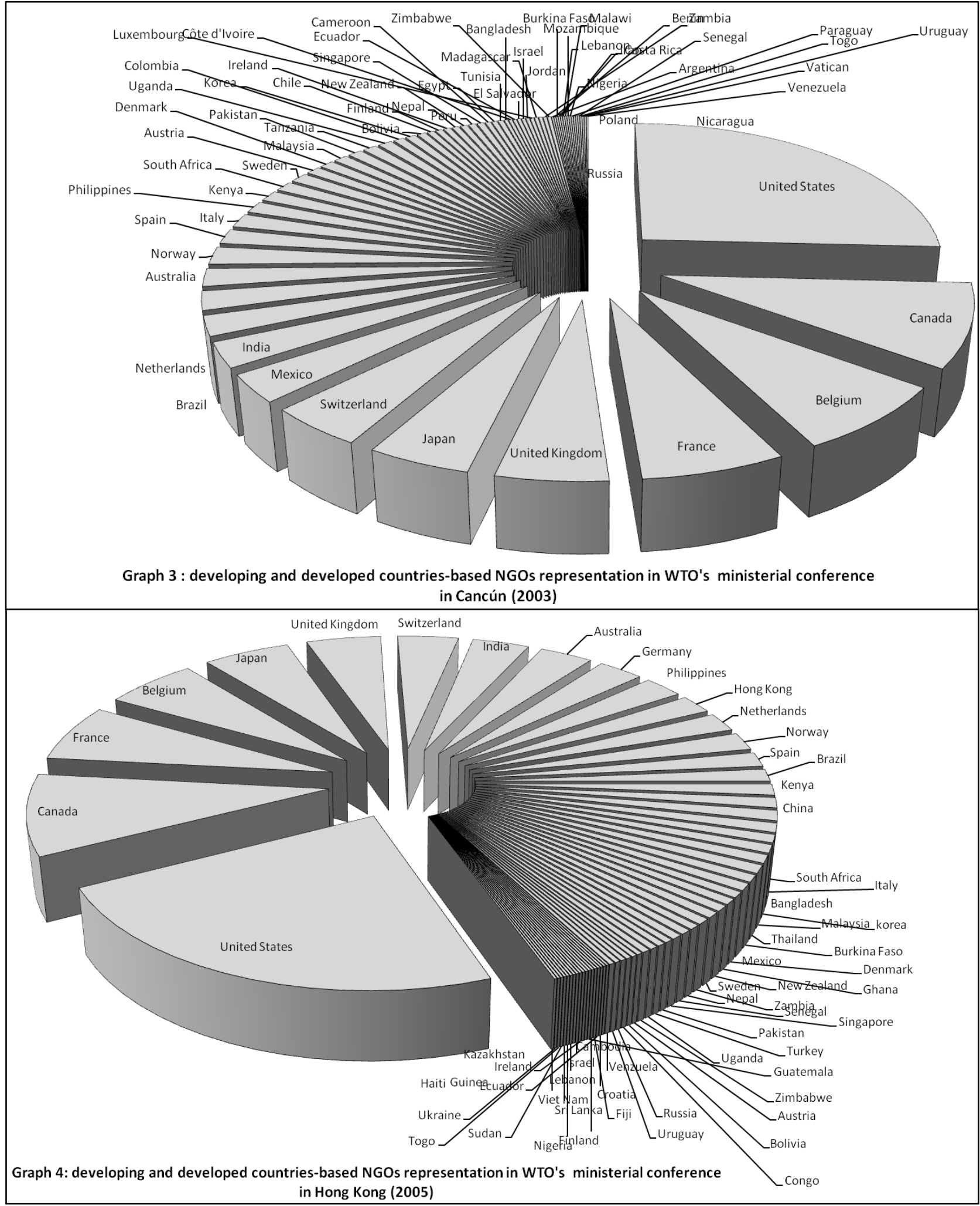




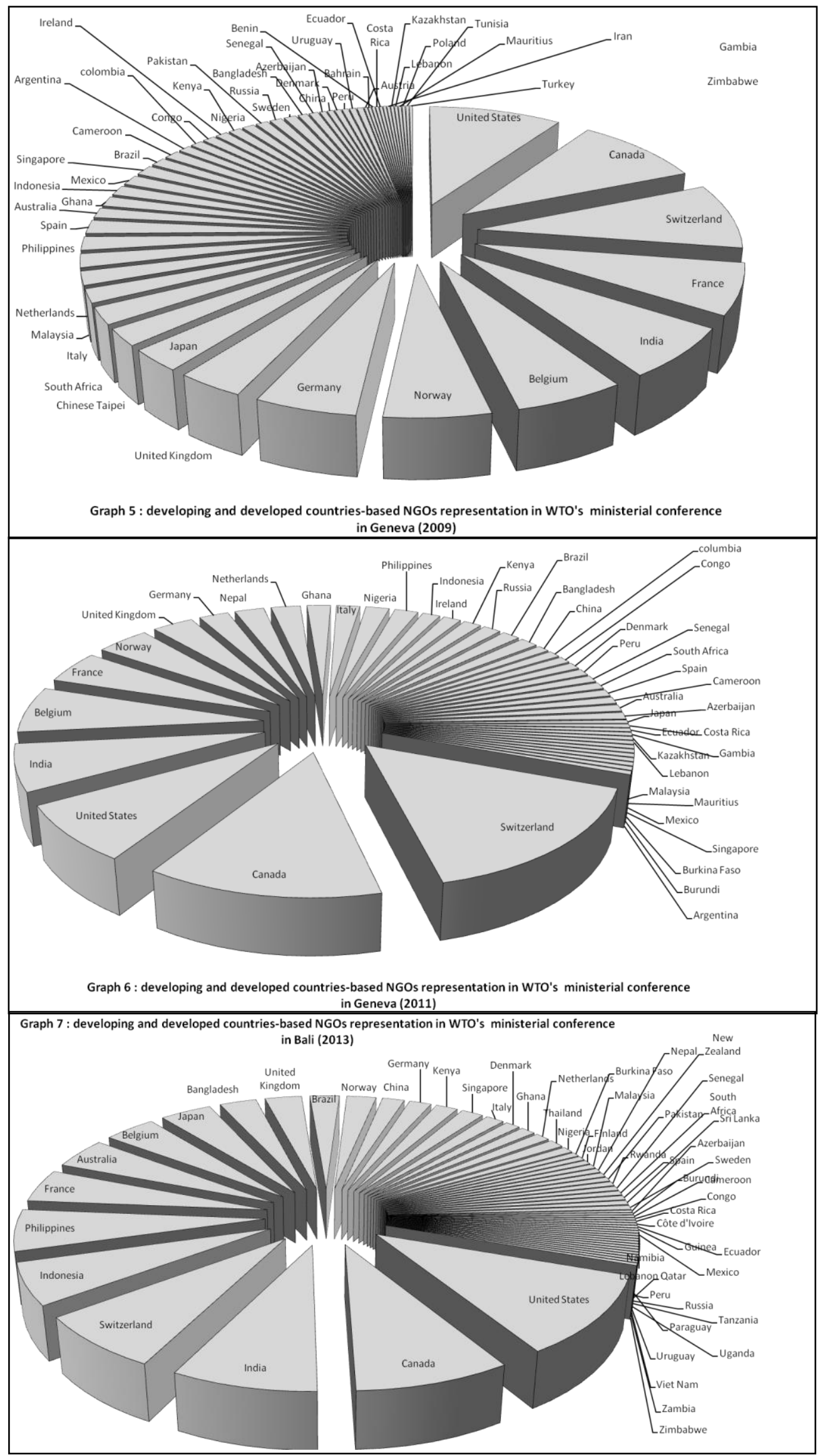

